American J. of Engineering and Applied Sciences 2 (1): 31-38, 2009

ISSN 1941-7020

(C) 2009 Science Publications

\title{
Reliability of Axially Loaded Fiber-Reinforced-Polymer Confined Reinforced Concrete Circular Columns
}

\author{
Venkatarman Nagaradjane, Pulipaka Narasimharao Raghunath and Kannan Suguna \\ Department of Civil Structural Engineering, Annamalai University, India
}

\begin{abstract}
Monte-Carlo simulation based procedure was applied for assessing the reliability of Fiber Reinforced Polymer (FRP) confined reinforced concrete columns. Assessment of reliability provides a quantitative measure of effectiveness of repair. Problem statement: The procedure presented in the paper could be used for assessing the reliability of reinforced concrete columns before and after the application of FRP wrap, thus helping to quantitatively assess the effectiveness of repair. The equations provided in ACI 440.2R were used for formulating the reliability equations Approach: Java based computer program was developed to assess the reliability of circular concrete columns strengthened using FRP composites. The influence of diameter, thickness of wrap, longitudinal steel and elasticity modulus of wrap on reliability was studied. Results: The results indicated that the diameter of column and wrap thickness strongly influenced the reliability of columns Conclusion/Recommendations: The influence of internal steel reinforcement area and elasticity modulus of fiber reinforced polymer on reliability was very limited. Computationally efficient formulation for estimating reliability was proposed. The new equation estimated reliability by up to 1575.2314 times faster than the common equation, thus resulting in the saving of time and computational power.
\end{abstract}

Key words: Confinement, FRP, monte-carlo simulation, normal distribution, reliability, reliability index, random number

\section{INTRODUCTION}

Repair and rehabilitation of reinforced concrete columns is necessitated by several factors like corrosion of reinforcement, damage due to vehicular collision, deterioration of core concrete due to environmental factors or an increase in the service loads of bridge like structures caused by ever expanding vehicular traffic. FRP is a composite material formed out of a variety of small diameter fibers (made of glass, carbon and aramid held in place using polymer resins. The application of FRP on the surface of concrete columns provides additional axial strength due to the resistance to lateral expansion offered by the FRP wraps thus reducing the axial deformation, consequent axial strain and resulting in more strength for core concrete. FRP improves the compressive ductility of concrete columns enormously due to the fact that FRP takes large strain before failure thus increasing the lateral dilation of concrete manifold. Incidentally, FRP arrests the ingress of moisture and other degrading agents, resulting in more durability for the core concrete.

Measurement of the level of repair and rehabilitation of structural members is essential to justify the amount of money and materials spent on repair and to ensure that the repair has resulted in measurable improvement in performance. Reliability is a statistical tool suitable for measuring performance of any structural system against performance requirements. Reliability is associated with the statistical probability that a structural member will survive the demand for performance imposed under service conditions. Probability of failure is the complementary part of the reliability of a structural element, accounting for the possibility that the element will fail under service conditions. Hence, the objective of repair or rehabilitation is to maximize reliability or to minimize probability of failure after repair or rehabilitation is work is carried out.

One of the techniques used for estimating reliability of structural systems is Monte Carlo simulation. This technique permits modeling of structural systems using the parameters affecting their behavior. Monte Carlo is general purpose method and its applications are found in wide ranging areas of social science, traffic flow, population growth, finance, genetics, quantum chemistry and radiation sciences ${ }^{[1]}$.

Corresponding Author: Venkatarman Nagaradjane, Department of Civil Structural Engineering, Annamalai University, India 
Assessment of reliability provides a quantitative tool for strengthening, repair and rehabilitation of reinforced concrete columns with FRP wraps. The present study is significant in that a framework for computing reliability is proposed based on the basic relationships for compressive strength of confined concrete provided in ACI 440.2R. The study also attempts to investigate the relationship between reliability and the column parameters like diameter of confined column, thickness of FRP wrap, area of longitudinal steel and elasticity modulus of FRP sheets.

Ruiz and Aguiler evaluated reliability indices for reinforced concrete short slender columns using MonteCarlo simulation technique ${ }^{[2]}$. The study revealed that the slenderness ratio, longitudinal steel, eccentricity and load levels were the significant parameters affecting reliability of reinforced concrete columns.

Dinz and Frangopal analyzed the bases for reliability assessment of high strength reinforced concrete columns ${ }^{[3]}$. The effect of load and unmagnified moments on slender high strength concrete columns. The study proposed a reliability based method for the assessment of high strength concrete columns.

Dinz and Frangopal studied the reliability of high strength concrete columns designed according to the American Concrete Institute provisions ${ }^{[4]}$. A combination of first order reliability method and Monte-Carlo simulation was adopted to evaluate the reliability of short as well as slender columns. The study found that short high strength concrete columns have lower reliability than normal strength concrete columns. Longitudinal steel reinforcement played a significant role on the reliability of slender high strength concrete columns.

Val studied the reliability of FRP confined, short, circular shaped reinforced concrete columns considering reinforcement ratio, live load to dead load ratio and eccentricity as the major parameters ${ }^{[5]}$. The study concluded that the load reduction factors were to be further reduced to ensure the level of reliability of unconfined column is comparable to that of FRP confined column. The study identified compressive strength of confined concrete, uncertainty coefficient for FRP confined concrete, error of the structural model and live load as the most influential parameters.

Tools and methods: Nominal strength of FRP confined concrete cylinders is influenced by the presence of internal steel ties, their spacing and configuration. ACI committee report $440.2 \mathrm{R}$ specifies that the compressive strength of concrete cylinders with spiral steel ties should be calculated using the expression ${ }^{[6,7]}$ :

$$
\varphi \mathrm{P}_{\mathrm{n}}=0.85 \varphi\left[0.85 \psi_{\mathrm{f}} \mathrm{f}_{\mathrm{cc}}^{\prime}\left(\mathrm{A}_{\mathrm{g}}-\mathrm{A}_{\mathrm{st}}\right)+\mathrm{f}_{\mathrm{y}} \mathrm{A}_{\mathrm{st}}\right]
$$

Where:

$\mathrm{P}_{\mathrm{n}}=$ The nominal axial compressive strength

$\varphi=$ The strength reduction factor

$\psi_{\mathrm{f}}=$ The additional FRP strength reduction factor (recommended value is 0.95 )

$\mathrm{f}_{\mathrm{cc}}=$ The apparent compressive strength of confined concrete

$\mathrm{A}_{\mathrm{g}}=$ The gross cross - sectional area

$A_{s t}=$ The total area of longitudinal reinforcement

$\mathrm{f}_{\mathrm{y}} \quad=$ The yield strength of non-prestressed steel reinforcement

For confined concrete with circular steel ties, the nominal compressive strength can be estimated using Eq. 2:

$$
\varphi \mathrm{P}_{\mathrm{n}}=0.80 \varphi\left[0.85 \psi_{\mathrm{f}} \mathrm{f}_{\mathrm{cc}}^{\prime}\left(\mathrm{A}_{\mathrm{g}}-\mathrm{A}_{\mathrm{st}}\right)+\mathrm{f}_{\mathrm{y}} \mathrm{A}_{\mathrm{st}}\right]
$$

ACI $440.2 \mathrm{R}$ recommends that the value of the additional reduction factor $\psi_{\mathrm{f}}$ be taken 0.95 . As a general case, the two equations can be combined into a third equation, by introducing an additional $\eta$, which stands for the effectiveness of the internal steel ties in providing confinement and is 0.85 for spiral ties and 0.80 for circular ties:

$$
\varphi \mathrm{P}_{\mathrm{n}}=\eta \varphi\left[0.85 \psi_{\mathrm{f}} \mathrm{f}_{\mathrm{cc}}^{\prime}\left(\mathrm{A}_{\mathrm{g}}-\mathrm{A}_{\mathrm{st}}\right)+\mathrm{f}_{\mathrm{y}} \mathrm{A}_{\mathrm{st}}\right]
$$

Further, the value of strength reduction factor $\varphi$ should be taken at 0.7 for compression members without spiral ties and at 0.75 for compression members with spiral ties satisfying the condition:

$$
\rho_{\mathrm{s}}=0.45\left(\frac{\mathrm{A}_{\mathrm{g}}}{\mathrm{A}_{\mathrm{c}}}-1\right) \frac{\mathrm{f}_{\mathrm{c}}^{\prime}}{\mathrm{f}_{\mathrm{y}}}
$$

Where:

$\rho_{\mathrm{s}}=$ The ratio of volume of spiral reinforcement to the core volume

$\mathrm{A}_{\mathrm{c}}=$ The core area of confined concrete measured up to the outside of the spiral ties

The confined compressive strength of concrete $\left(\mathrm{f}_{\mathrm{cc}}\right)$ is to be evaluated using the model proposed by Mander et al. ${ }^{[8]}$ :

$$
\mathrm{f}_{\mathrm{cc}}=\mathrm{f}_{\mathrm{c}}\left[2.25 \sqrt{1+7.9 \frac{\mathrm{f}_{1}}{\mathrm{f}_{\mathrm{c}}^{\prime}}}-2 \frac{\mathrm{f}_{1}}{\mathrm{f}_{\mathrm{c}}^{\prime}}-1.25\right]
$$


The parameter $f_{l}$ stands for the effective confinement pressure generated by the passive confining mechanism of FRP wrap. The value of $f_{1}$ can be estimated using the expression:

$$
\begin{aligned}
& \mathrm{f}_{\mathrm{l}}=\frac{\kappa_{\mathrm{a}} \rho_{\mathrm{f}} \varepsilon_{\mathrm{fe}} \mathrm{E}_{\mathrm{f}}}{2} \\
& \varepsilon_{\mathrm{fe}}=0.004 \leq 0.75 \varepsilon_{\mathrm{fu}} \\
& \rho_{\mathrm{f}}=\frac{4 \mathrm{nt}_{\mathrm{f}}}{\mathrm{D}}
\end{aligned}
$$

where, $\kappa_{\mathrm{a}}$ is the confinement effectiveness factor which depends on the shape of cross-section, value being unity for a circular section and less than unity for noncircular sections, $\rho_{\mathrm{f}}$ is the area of composite to area of concrete per unit height of the column section, $\mathrm{n}$ is the number of layers of FRP, $\varepsilon_{\mathrm{fe}}$ is the effective strain in FRP, $E_{f}$ is the elasticity modulus of FRP, $\varepsilon_{f u}$ is the ultimate strain for FRP, $t_{f}$ is the thickness of FRP and D is the diameter of the concrete column for circular sections.

Hence, the actual process of estimation of the compressive strength of FRP confined reinforced concrete columns begins with the calculation of maximum confining pressure using Eq. (6) followed by computation of the strength of confined plain concrete using Eq. (5). The confined plain concrete strength is substituted in the appropriate Eq. 1 or 2 recommended by ACI, based on the type of tie provided for column (whether circular or spiral). In case the column is provided with spiral ties, the volume of ties to core volume should satisfy the condition suggested by ACI (as represented by Eq. 4).

The deterministic formulation of strength estimation for FRP confined reinforced concrete columns forms the basis for the probabilistic simulation of strength using Monte Carlo technique. The basic equations and procedure remaining the same as that for deterministic evaluation of strength, Monte Carlo simulation simply permits random variations in all properties and parameters involved in the equations within allowable limits. This situation mimics the result of a real world experiment which is also subject to reasonable levels of uncertainty resulting from the fact that that material properties deviate from designated mean values.

Reliability as a measure of structural performance: All design codes and guidelines provide a way for ensuring that the structural member will survive the specified loading conditions. Design procedures of different codes lead to different levels of economy. This is because safety level is taken as a qualitative factor where a structural element is permitted to have arbitrary levels of excess strength. But Reliability (R) provides rational approach to safety by quantifying the level of safety associated with a particular combination of materials. Hence, reliability can be used to assess the degree of conservatism associated with the deterministic analysis ${ }^{[9]}$.

Reliability might be defined as the probability that a structural system will survive the given load level. There is a counterpart to reliability called probability of failure $\left(\mathrm{P}_{\mathrm{f}}\right)$. It is defined as the probability that a structural system will fail under the given loading conditions. Hence, reliability and probability of failure form two extremes related to the safety of structural systems. Probability theory states that the sum of reliability and probability of failure is always equal to unity. This rule makes it easy to evaluate one quantity if the other one is known.

In the normal probability distribution space the frequency $(y)$ associated with each numeric value $(x)$ is calculated using the expression:

$$
y=\frac{e^{-x^{2} / 2}}{\sqrt{2 \pi}}
$$

The plot of which is shown in Fig. 1. The probability of failure is represented by the shaded area and the reliability is represented by the un-shaded area. The negative of value at which the areas of reliability and probability of failure meet is called the reliability index $(\beta)$. Reliability index $(\beta)$ value zero is associated with reliability 0.5 .

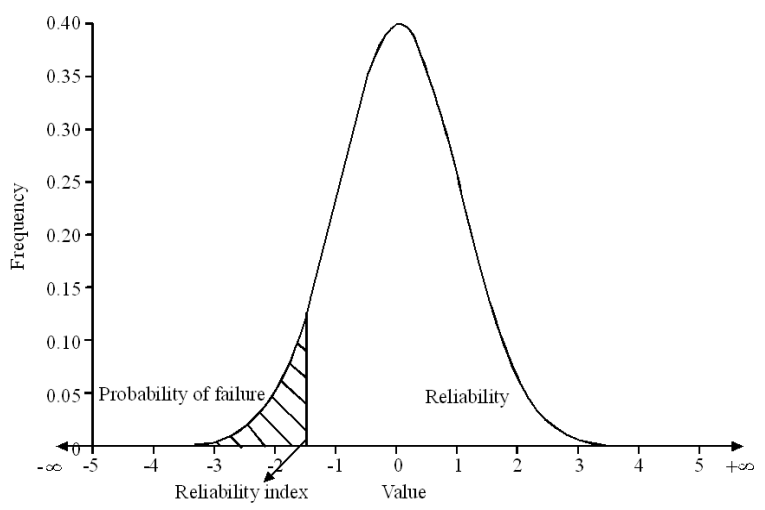

Fig. 1: Relation between reliability, probability of failure and reliability index in normal distribution space 
The relationship being clear, knowing any one of the three parameters $\mathrm{R}, \mathrm{P}_{\mathrm{f}}$ or $\beta$, calculation of the other two parameters is possible. Knowing reliability index $(\beta)$, the probability of failure and reliability can be found out using the relations:

$$
\begin{aligned}
& P_{f}=\int_{-\infty}^{-\beta} \frac{e^{\frac{-x^{2}}{2}}}{\sqrt{2 \pi}} d x \\
& R=1-P_{f}
\end{aligned}
$$

Sometimes, the probability of failure is known before hand. Reliability index can be evaluated by carrying out the integration from negative infinity up to such a point on the normal distribution curve that the area equals the known probability of failure. The negative of the value on the $\mathrm{x}$ - axis is the reliability index. Alternatively, reliability index can be visualized as the ratio between mean level of safety and standard deviation in safety and calculated using the expression:

$$
\beta=\frac{\mu_{\mathrm{r}}-\mu_{\mathrm{a}}}{\sqrt{\sigma_{\mathrm{r}}^{2}+\sigma_{\mathrm{a}}^{2}}}
$$

Where:

$\mu_{\mathrm{r}}=$ The mean resistance of the system

$\mu_{\mathrm{a}}=$ The mean action or load on the system

$\sigma_{\mathrm{r}}=$ The standard deviation in resistance of the system

$\sigma_{\mathrm{a}}=$ The standard deviation in action or load on the system

The three major parameters of safety being defined, estimation of these parameters is possible using Eq. 8-10.

Monte carlo simulation for assessment of structural reliability: Reliability of FRP structural systems can be estimated using techniques like First Order Reliability Method (FORM $)^{[10]}$, First Order Second Moment Reliability Method (FOSMRM) ${ }^{[11]}$ and Monte Carlo Simulation ${ }^{[10]}$. The FORM and FOSMRM employ Taylor's series expansion for estimating mean and standard deviation in member strength and performance demands, thus permitting calculation of reliability index (Eq. 10). Knowing the reliability index, probability of failure and reliability can be estimated using Eq. 8 and 9 respectively.

The present work employs monte carlo simulation for estimating reliability of structural members. Monte carlo simulation procedure involves generating random values for non-deterministic input parameters, estimating the strength using the randomly chosen values and checking whether the performance meets structural demand. If the estimated performance of the structure does not meet the performance demand it is counted as a failure. Probability of failure is estimated as the ratio between the number of failures and the total number of runs:

$$
\mathrm{P}_{\mathrm{f}}=\frac{\sum_{\mathrm{i}=1}^{\mathrm{N}}<\mathrm{S}_{\mathrm{a}}-\mathrm{S}_{\mathrm{r}}>}{\mathrm{N}}
$$

Where:

$\mathrm{S}_{\mathrm{r}}=$ The simulated resistance

$\mathrm{S}_{\mathrm{a}}=$ The simulated action or load acting on the member

$\mathrm{N}=$ The number of runs of the Monte Carlo simulation process

The triangular brackets $(<>)$ stand for McAuley bracket function, which yields one if the result is positive and zero otherwise. Hence, the summation counts only the number of failures (or the number of simulated runs which resulted in less resistance than required). The random parameter value of each parameter $\mathrm{X}$ is generated using:

$$
\begin{aligned}
X=\bar{X}+k r \sigma_{x} \\
\quad c=\int_{-k}^{+k} \frac{e^{-x^{2} / 2}}{\sqrt{2 \pi}} d x
\end{aligned}
$$

Where:

$\mathrm{X}=$ The mean value of the parameter

$\mathrm{K}=$ The spread constant which corresponds to the given confidence level

$\mathrm{R}=$ The generated random value lying between -1 and $+1$

$\sigma_{\mathrm{x}}=$ The standard deviation in the population of $\mathrm{X}$

$\mathrm{c}=$ The confidence level

The simulation process takes confidence level as input and evaluates the constant $\mathrm{k}$ using the relationship 13 .

Implementation of monte carlo simulation algorithm: Monte Carlo Simulation algorithm for estimating the reliability of FRP confined reinforced concrete columns is presented as follows:

- Generating random parameter values for column geometry

- Generating random parameter values for steel reinforcement properties 
Am. J. Engg. \& Applied Sci., 2 (1): 31-38, 2009

- Generating random parameter values for FRP properties

- Estimating the load carrying capacity of reinforced concrete column using Eq. 1-6 as necessary

- Generating random load on the column using mean load, standard deviation in load and the confidence level used

If the load carrying capacity turns out to be less than the load placed on the column, the situation is counted as a failure.

The above steps are repeated for predetermined number of runs. The larger the number of runs, the lesser is the error associated with the results.

Probability of failure is calculated as the ratio between number of failures and total number of runs.

The algorithm was implemented in Java programming language. The software was called Monte Carlo Simulator for Fiber Reinforced Polymer Confined Column (MCS-FRPCC) and was developed on Fedora Core 2 Linux operating system using Java Development Kit (JDK) version 1.6. The source can be obtained from the corresponding author free of cost.

Optimization for faster performance: The software was tested for time consumption against computation of random numbers, simulation of column parameters and computation of reliability index. It was found that a lot of time was consumed for evaluating the reliability index using Eq. 8. Although Eq. 8 is mathematically correct, it suggests numerical integration from negative infinity up to the point where desired probability of failure is reached. It takes a long time to perform numerical integration from an extremely negative value. Hence, an alternative equation was formulated to evaluate reliability index.

$$
\begin{aligned}
& \mathrm{R}=\frac{1}{2}+\frac{(\beta)}{\|\beta\|} \int_{0}^{\beta} \frac{\mathrm{e}^{\frac{-x^{2}}{2}}}{\sqrt{2 \pi}} \mathrm{dx} \quad \text { for } \beta \neq 0 \\
& \mathrm{R}=\frac{1}{2} \quad \text { for } \beta \neq 0
\end{aligned}
$$

This formulation uses the basic property that the area under normal distribution curve from zero to positive infinity is $1 / 2$. This proposition shifts the lower limit of integration to zero point rather than positive infinity or negative infinity. Hence, reliability index $(\beta)$ is found out by numerical integration from zero to until the summation equals desired reliability. The summation from integration is added to $1 / 2$ when reliability is greater
Table 1: Time Consumptions for alternative evaluation schemes of

\begin{tabular}{|c|c|c|c|c|}
\hline $\begin{array}{l}\text { Sl. } \\
\text { No. }\end{array}$ & $\begin{array}{l}\text { Interval on } \\
\mathrm{X} \text {-axis }(\mathrm{dx})\end{array}$ & $\begin{array}{l}\text { Average time } \\
\text { taken by Eq. } 8 \\
(\text { milli sec) }\end{array}$ & $\begin{array}{l}\text { Average time } \\
\text { taken by Eq. } 14 \\
\text { (milli sec) }\end{array}$ & $\begin{array}{l}\text { Time } \\
\text { ratio }\end{array}$ \\
\hline 1 & 0.1000 & 72.7143 & 7.5918 & 9.5780 \\
\hline 2 & 0.0100 & 513.6531 & 6.5510 & 78.4081 \\
\hline 3 & 0.0010 & 4984.8163 & 78.5510 & 63.4596 \\
\hline 4 & 0.0001 & 47650.7500 & 30.2500 & 1575.2314 \\
\hline
\end{tabular}
reliability index

than 0.5 and subtracted from $1 / 2$ when reliability is less than $1 / 2$, since the value of $(\beta) /|\beta|$ simply gives the sign (whether positive or negative) of the expression being integrated.

Table 1 shows the time averages for calculating reliability index ( $\beta$ ) using Eq. 8 and 14 . The measurements were made on a Fedora core 2 Linux operating system running on AMD Sempron processor clocked at $1400 \mathrm{MHz}$ with $256 \mathrm{MB}$ of RAM. While the actual times may vary on other systems, the time ratio is expected to provide an estimate of how fast the new algorithm works, especially when the interval for numerical integration $(\mathrm{dx})$ is reduced from larger values to smaller values.

\section{MATERIALS AND METHODS}

The present parametric study was performed for $150 \mathrm{~mm}$ (5.906 inches) diameter reinforced concrete circular column confined with $3 \mathrm{~mm}$ (0.118 inch) thick GFRP wrap having elasticity modulus of $10200 \mathrm{MPa}$ (520062.94 lbf/sq. in). The internal steel reinforcement was $315 \mathrm{~mm}^{2}(0.488$ sq. inch $)$ and steel ties were spaced at $115 \mathrm{~mm}$ (4.528 inch) c/c. The compressive strength of concrete was $23.64 \mathrm{MPa}(2657 \mathrm{lbs} / \mathrm{sq}$. inch), yield strength of steel was $415 \mathrm{MPa}(46643.61 \mathrm{lbf} / \mathrm{sq}$. in), ultimate tensile strain in FRP was 0.016.

The basic requirements for the computation of reliability index of FRP wrapped reinforced concrete column are an equation which describes the load carrying capacity of the column for given material properties (concrete, steel and FRP), the load level. The mean values and their standard deviations for all material properties and loading values are also required for simulation.

The influence diameter of column and load carrying capacity on reliability was studied by choosing diameters ranging from $100 \mathrm{~mm}$ (3.94 inches) to $1000 \mathrm{~mm}$ (39.37 inches), keeping all other parameters constant. The imposed compressive load was varied from the lower bound value (corresponding to $100 \mathrm{~mm}$ (3.94 inches) diameter) to the upper bound value (corresponding to $1000 \mathrm{~mm}$ (39.37 inches) diameter). 


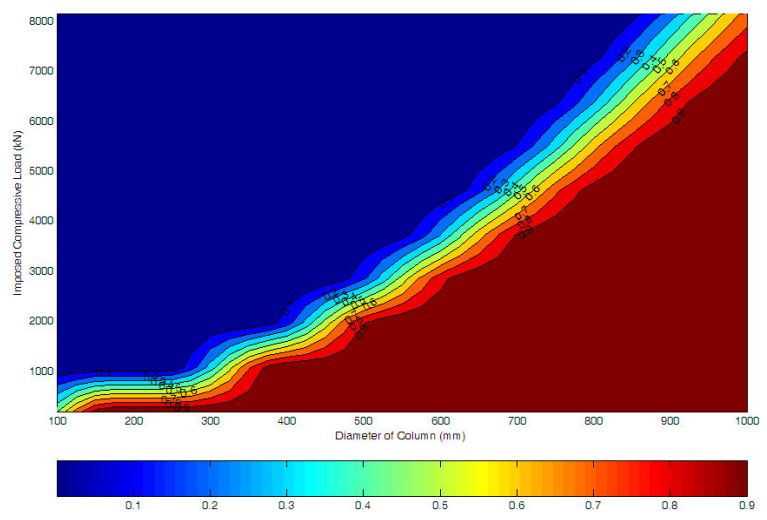

Fig. 2: Reliability as a function of column diameter and imposed compressive load

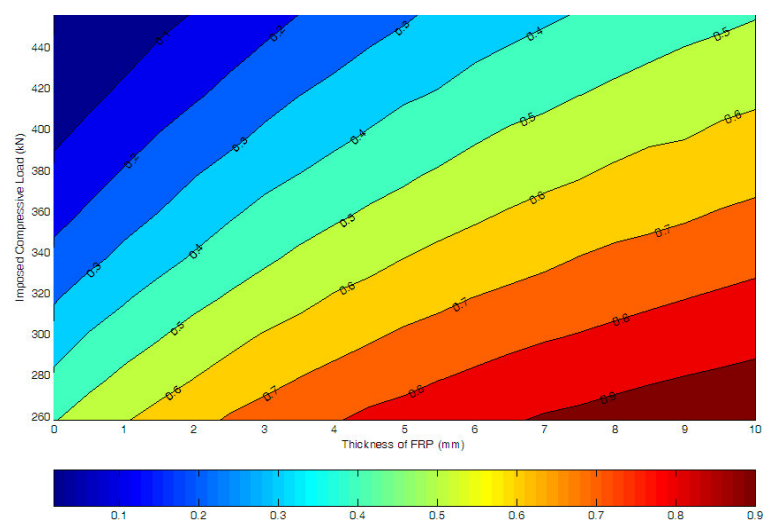

Fig. 3: Reliability as a function of thickness of FRP and imposed compressive load

\section{RESULTS}

The influence of parameters like diameter of column, thickness of FRP wrap, area of longitudinal steel and elasticity modulus of FRP wrap was studied using the software framework. The reliability values were plotted in contour form as a function of the given parameter and imposed load. The reliability contour plotted as a function of diameter and the demanded load carrying capacity is shown in Fig. 2.

Figure 3 shows the reliability contour plotted as a function of thickness of FRP and imposed compressive load. The findings are in agreement with those reported by $\mathrm{Val}^{[5]}$. Figure 4 shows the reliability contour as a function of area of longitudinal reinforcement and compressive load applied on the column. Figure 5 shows the reliability contour as a function of elasticity modulus and imposed compressive loads. The contour boundaries for reliability have a tendency to drift from their mean path.

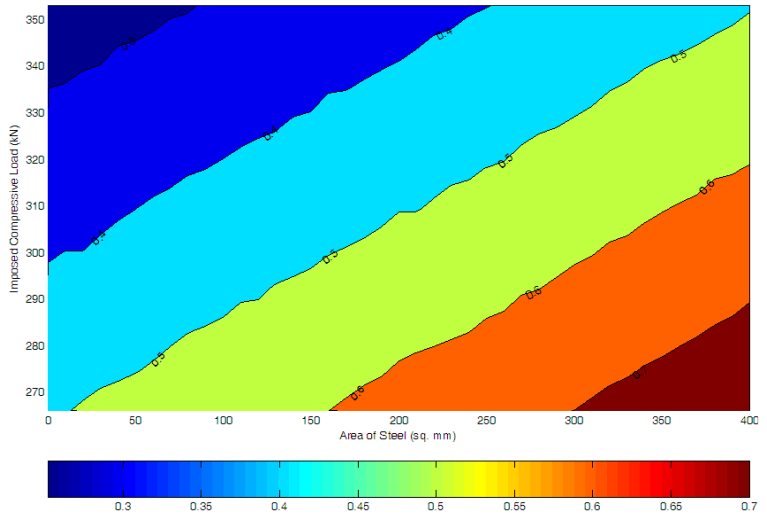

Fig. 4: Reliability as a function of area of steel and imposed compressive load

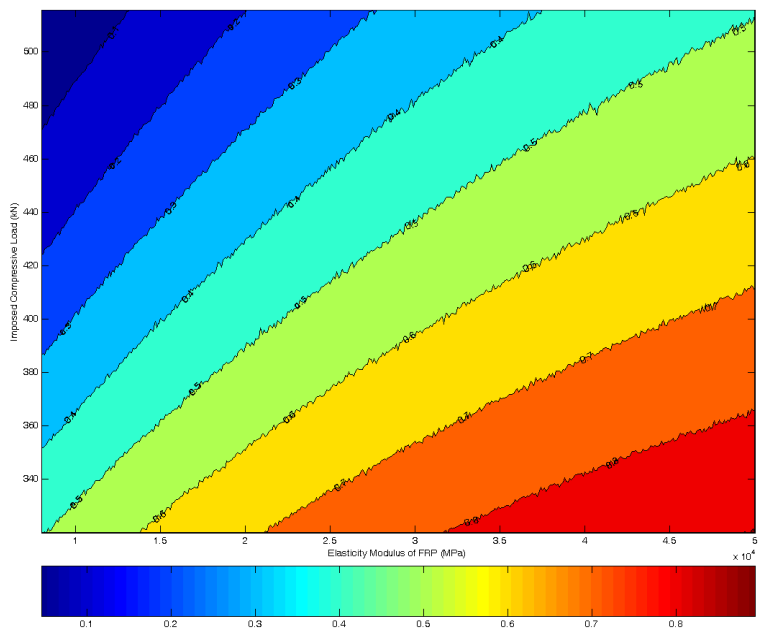

Fig. 5: Reliability as a function of elasticity modulus of FRP and imposed compressive load

\section{DISCUSSION}

The results indicated that reliability was significantly affected by diameter of column, thickness of FRP, area of internal steel reinforcement and elasticity modulus of FRP.

The imposed loads were calculated for the lower bound and upper bound values of the parameter being studied. When a single parameter was subjected to variation, all others were kept constant. With increasing diameter of column, the reliability went on increasing and reached the maximum value 1.0. Increasing the applied load led to a reduction in the reliability of the column, reaching a minimum value of 0 . Increasing thickness of FRP wrap improved the reliability of confined RC column. Without any wrap, the reliability value was around 0.5 for lower-bound compressive load 
of $260 \mathrm{kN}$ (58450.33 lbf). For the same imposed load, reliability reached 0.8 for $4 \mathrm{~mm}(0.16$ inch) wrap and 0.9 for $7 \mathrm{~mm}$ (0.28 inch) wrap. For higher imposed loads, the increase in reliability was lower. At loads around $450 \mathrm{kN}$ (101164.02 lbf), reliability reached 0.28 for $4 \mathrm{~mm}$ thick wrap and 0.5 for $10 \mathrm{~mm}$ thick wrap.

Area of longitudinal reinforcing steel affected the reliability values only in the range of $0.3-0.7$. This meant that FRP wrap itself played a role towards improving the reliability of RC column. Increasing the presence of steel up to $400 \mathrm{~mm}^{2}$ (0.620 sq. in.) led to increase in reliability value up to 0.7 . Hence, the internal steel reinforcement might be inferred as a significant parameter, but its role was complementary in the presence of FRP wrap.

Elasticity Modulus of FRP was varied from $8000 \mathrm{MPa}$ (407892.5 lbf/sq. in) to $50000 \mathrm{MPa}$ (2549328.125 lbf/ sq. in) and the corresponding imposed compressive loads varied from $320 \mathrm{kN}$ (71938.86 lbf) to $515.83 \mathrm{kN}(115963.20 \mathrm{lbf})$. For the imposed load of $320 \mathrm{kN}$ (7193.86 lbf) the reliability started at 0.5 for elasticity modulus of $8000 \mathrm{MPa}$ (407892.5 lbf/sq. in), reached a value of 0.8 for elasticity modulus of $31000 \mathrm{MPa}$ (1580583.44 lbf). For the high end load of $515.83 \mathrm{kN}$ (115963.20 lbf), the reliability starts near 0 for FRP elasticity modulus of $8000 \mathrm{MPa}(407892.5 \mathrm{lbf} / \mathrm{sq}$. in) and reaches about 0.5 for that of $50000 \mathrm{MPa}(2549328.125 \mathrm{lbf} / \mathrm{sq}$. in).

\section{CONCLUSION}

Assessment of reliability of reinforced concrete columns provides a rational means of scheduling repair and rehabilitation works, deciding the type of repair and amount of repair. In case of columns on which FRP is installed as a wrapping for strengthening or rehabilitation works, the improvement in reliability provides a quantitative measure of the amount of improvement in strength. The following conclusions are drawn from the investigation:

- The diameter of reinforced concrete column was a vital parameter for the reliability of reinforced concrete columns confined by FRP wraps. The closely spaced contour lines indicated that even small variations in diameter of RC column with FRP wrap resulted in measurable change of reliability

- Thickness of FRP wrap was also identified as a major parameter to assess the reliability of confined concrete columns

- Area of internal steel reinforcement played a moderate role in improving the reliability of FRP confined column. The variations in area of internal steel did have a low contribution to reliability of FRP confined reinforced concrete columns

- Elasticity modulus of FRP wrap was studied in a widely varying range of values. The increase in reliability was not reflective of the increase elasticity modulus. Increasing elasticity modulus from $25000 \mathrm{MPa}(1274664.07 \mathrm{lbf} / \mathrm{sq}$. in) to 50000 $\mathrm{MPa}$ (2549328.13 lbf / sq. in) shifted the reliability from $0.7-0.8$

- Computationally efficient formulation for estimating reliability was proposed. The new equation estimated reliability by up to 1575.2314 times faster than the common equation, thus resulting in the saving of time and computational power

- The revised procedure proposed in this work might be used in future works for faster estimation of the reliability parameters.

- The Graphical User interface (GUI) based software developed as part of this work was suitable for assessing reliability of FRP confined concrete columns based on ACI 440.2R

\section{ACKNOWLEDGEMENT}

The researchers acknowledge the financial support offered by University Grants Commission (UGC) of India, New Delhi, for carrying out investigations on FRP confined concrete columns.

\section{REFERENCES}

1. Kamiński, M. and T. Trapko, 2006. Experimental behavior of reinforced concrete column models strengthened by CFRP materials. J. Civil Eng. Manage., 12: 109-115.

http://www.jcem.vgtu.lt/upload/civil_zurn/kaminsk i\%20and\%20trapko.pdf

2. Ruiz, S.E. and J.C. Aguiler, 1994. Reliability of short and slender reinforced concrete columns. ASCE J. Struct. Eng., 120: 1850-1865. DOI: 10.1061/(ASCE)0733-9445(1994)120:6(1850)

3. Dinz, S.M. and D.M. Frangopal, 1997. Reliability bases for high strength concrete columns. ASCE J. Struct. Eng., 123: 1375-1381. DOI: 10.1061/(ASCE)0733-9445(1997)123:10(1375)

4. Dinz, S.M. and D.M. Frangopal, 1998. Reliability assessment of high strength concrete columns. ASCE J. Eng. Mechanics, 124: 529-536. DOI: 10.1061/(ASCE)0733-9399(1998)124:5(529) 
5. Val, D.V., 2003. Reliability of fibre-reinforced polymer confined reinforced concrete columns. ASCE J. Struct. Eng., 129: 1122-1130. DOI: 10.1061/(ASCE)0733-9445(2003)129:8(1122)

6. ACI Committee 318, 1999. Building Code Requirements for Reinforced Concrete, American Concrete Institute, Detroit, USA. http://www.concrete.org/pubs/newpubs/318-08.htm

7. ACI Committee 440.2R 2002. Guide for the Design and Construction of Externally Bonded FRP Systems for Strengthening Concrete Structures. http://www.concrete.org/bookstorenet/ProductDeta il. aspx $?$ SACode $=440202$
8. Mander, J.B., M.J.N. Priestley and R. Park, 1988. Theoretical stress-strain model for confined concrete. J. Struct. Eng., ASCE, 114: 1804-1826.

9. Sarveswaran, V., M.B. Robers and J.A. Ward, 2000. Reliability assessment of deteriorating reinforced concrete beams. Proc. Instn. Civil Eng., Struct. $\quad$ Build., 239-248. DOI: 10.1680/stbu.152.1.83.40887

10. Rao, S.S., 1992. Reliability-Based Design. McGraw-Hill, New York, pp: 1-569. 